\title{
Well-being innovation platform projects of the North-West University: Evaluative perceptions of community participants
}

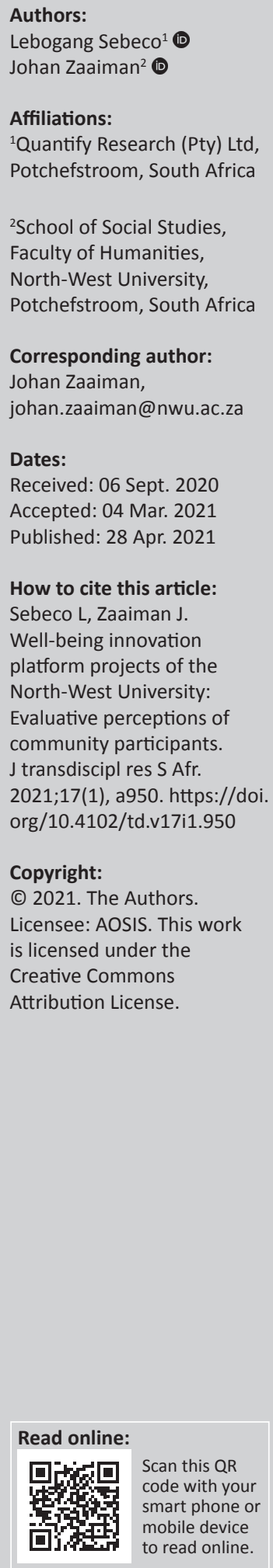

Authors:

Affiliations:

${ }^{1}$ Quantify Research (Pty) Ltd,

${ }^{2}$ School of Social Studies,

Faculty of Humanities,

North-West University,

Corresponding author:

Johan Zaaiman,

Dates:

Accepted: 04 Mar. 2021

How to cite this article:

Sebeco L, Zaaiman J.

platform projects of the

North-West University:

Evaluative perceptions of

community participants.

res SA

org/10.4102/td.v17i1.950

Copyright:

(C) 2021. The Authors.

Licensee: AOSIS. This work

is licensed under the

Creative Commons
Community engagement referred to approaches in which communities were involved in activities that positively impacted their lives. Currently, higher education institutions have community engagement high on their agenda. This article focussed on how this engagement ought to be managed through the responses of community members to such an intervention. It presented community members' evaluative perceptions on the North-West University's (NWU) well-being innovation (WIN) platform projects in the Vaalharts community. This research was qualitative and a case study design was followed. Through interviews and focus groups, the perceptions of participants of the WIN platform projects were obtained. The data used stemmed from empirical research by the Human Sciences Research Council (HSRC) and the researchers. Although this study could reach only a limited number of project participants, they provided valuable insights into the ways they had experienced the projects. Guided by the Context-Focus-Profile model, a comprehensive evaluation framework was constructed for the interview and focus groups' schedules. The findings indicated that the community members had positive perceptions of the projects, which had contributed most especially to skills and self-development. However, as members of a poor community, such people are vulnerable. To ensure that they feel respected and that projects fit their needs to ensure longlasting benefits, the way in which community engagement was conducted was important. Recommendations for improvement emerging from this study focussed on collaboration, communication, monitoring and recruitment. This article thereby contributed to the debate about higher education institutions' involvement in community engagement and demonstrated the value of using the Context-Focus-Profile model for evaluation purposes.

Keywords: higher education institutions; North-West University; community engagement; collaboration; Vaalharts; WIN platform projects; Context-Focus-Profile model; silo, intersectional and infusion models.

\section{Introduction}

The well-being innovation (WIN) platform was established in 2011 by the Africa Unit for Transdisciplinary Health Research (AUTHeR) in the Faculty of Health Sciences at the Potchefstroom Campus of the North-West University (NWU). The goal of the WIN platform was to improve rural health and well-being in the Vaalharts region, which falls under the Frances Baard District municipality and the Phokwane local municipality. Income for citizens in the Phokwane municipality depends largely on agriculture, community development projects and the informal economy. They are therefore vulnerable. The WIN platform implemented 18 projects, which were divided into three domains: (1) community engagement research, (2) service learning/workintegrated learning and (3) skills development projects. These domains focussed specifically on three aspects of well-being: (1) physical health (divided into sports and recreation), (2) socioeconomic factors and (3) psychosocial well-being. A multidisciplinary approach was followed and other faculties at the NWU were also involved.

This study forms part of an evaluation of the WIN platform conducted by AUTHeR. To build sustainable networks and partnerships further with the community, it was important to determine the community members' perceptions of the NWU's community engagement thus far. Decisionmaking, in the original implementation of the projects, had mainly been located in the university's WIN platform. ${ }^{1}$ This is not ideal for community engagement projects, however, ${ }^{2,3}$ as fuller collaboration is expected, especially those involving higher education environments. ${ }^{4,5}$ This point is also emphasised in the current NWU Community Engagement Policy. ${ }^{6}$ To make sure that future 
projects would be characterised by reciprocity, respect, trust, collaboration and participation, feedback from the community was needed. The objective of this study, therefore, was to obtain evaluative perceptions of community members about their community engagement experiences of the WIN platform. In the sections of this article that follow, the concept of community engagement is explained, followed by a reflection on higher education community engagement, the research methodology of this study, a report on the findings and a conclusion.

\section{Community engagement}

Community engagement is an overarching term for various approaches in which communities are involved in activities that positively impact their lives. ${ }^{7}$ Theoretically, different community engagement approaches yield different outcomes. However, a common expectation is that the involvement must be respectful, meaningful and fit-forpurpose in one or more phases of a project. $^{8}$ As Setswe and Witthuhn ${ }^{9}$ stated, community engagement is founded on principles of equality and justice. Engagement should acknowledge that barriers exist in providing certain services, which may be caused by a lack of understanding of local social and cultural processes. ${ }^{9}$ The assumption is that the more control community members are given in developing solutions to the problems they experience, the more likely it is that the standard of their lives will improve. ${ }^{7,10}$

\section{The World Bank refers to community engagement as:}

$[T]$ he process by which citizens' needs, concerns and values are incorporated into governmental decision-making; it is a twoway communication process with better overall goals of decisionmaking supported by the public. ${ }^{11}$

Omerikwa ${ }^{12}$ defined community engagement as 'the collaboration between institutions and their larger communities for the mutually beneficial exchange of knowledge and resources in a context of partnership and reciprocity'. Such engagement allows institutions to plan more suitable interventions and collaborative decisionmaking makes it easier for institutions to provide relevant quality service. ${ }^{13,14}$ Cristalli and Dulmus ${ }^{15}$ stipulated that it refers to shared responsibility, advancing the community to give its members better opportunities or capacity to be active role players as changes occur within their community.

Schlake $^{14}$ mentioned three principles for community engagement. The first principle ensures success in community engagement, it is important to involve the community in each stage of a project, from its development to its implementation. If people are not involved from the initial stages of the project, it is difficult to establish trust and the vulnerability of community members is further exposed. ${ }^{16}$ It is also important to include the key stakeholders or leaders of the community so as to understand their positions within the community and to remove any barriers to participation and future engagement. Involving persons with authority (e.g. leaders of certain departments) in community projects will ensure that doors are open for future participation. ${ }^{14}$ According to Glandon, Paina, Olonge, Peters and Bennett, ${ }^{8}$ this also ensures that power issues are addressed, that everyone is involved from the start and that there is equal distribution of power amongst the parties.

The second principle emphasises self-determination. The community must have a platform for identifying the challenges they face and the causes and to develop solutions and action plans for tackling such issues. They must also be involved in the implementation of the strategies they have developed to address these issues. ${ }^{8}$ This is important because, if the community members feel that they are given a voice and the opportunity to be active participants in projects that affect their lives, they are more likely to participate positively.

The third principle is that engagement must be reciprocal. Janke and Clayton ${ }^{17}$ defined reciprocity as the recognition, respect and valuing of the knowledge, perspective and resources that each partner contributes to the collaboration'. This ensures that there is an exchange of knowledge and colearning for both parties, which benefits everyone. Schlake ${ }^{14}$ emphasised equal distribution of power, transparency and equal decision-making opportunities. Collaboration is important for long-term partnerships to sustain progress, because high levels of collaboration develop the ability to address difficult challenges that communities face. ${ }^{14}$ The following section provides a discussion of community engagement in higher education institutions in South Africa.

\section{Higher education and community engagement}

South Africa's higher education system has been challenged to elevate the quality of teaching, learning and research in ways that encourage better engagement with the community. ${ }^{18}$ This challenge has given universities an interest in partnerships with communities that contribute to transfer of knowledge. ${ }^{19,20}$ These partnerships can foster an academic environment that is rooted in the real-life experience of such communities, thereby producing programmes that effectively address social issues faced by them. ${ }^{19,21}$ According to Rowe, ${ }^{22}$ higher education institutions have for a long time been perceived as being detached from social issues prevalent in communities; their focus has been more on academic functions and less on socio-economic development. Both Luvalo $^{23}$ and Kruss $^{24}$ stipulated that the slow rate of development in South Africa has created a need for the government to challenge higher education institutions to take part in upliftment. This is because these institutions have the capacity to produce skills and research that meet the needs of the economy. Boyer ${ }^{25}$ and Shannon and Wang ${ }^{20}$ concurred that institutions should extend their teaching and learning as well as research activities to deal critically with pressing issues communities face. Although the contribution of higher education institutions to society is mainly educational, researchers/academics are focusing more on the potential role they could play in contributing to development 
and adhering to their social responsibility to the community. ${ }^{12}$ Recently, community engagement became part of the mission statements of higher education institutions, mostly referred to as outreach, community service, service learning or community service teaching. ${ }^{26}$

The NWU decided to introduce community engagement into their core functions in 2014 after an indaba held by management and key stakeholders. ${ }^{6}$ It has developed a Success Model for 2025 to ensure that integration takes place between teaching, learning, research and community engagement. To achieve this goal for 2025, the university uses the approach of sharing expertise with the community for better-quality research, innovation and engagement. The sharing of expertise encourages reciprocity and community engagement. The NWU policy statement states that:

[S]taff and students must engage with their respective communities when conducting activities related to research/ innovation, teaching and learning, community service and outreach initiatives in an attempt to influence policy and address South Africa's developmental challenges and sustainability, thereby sharing its expertise. ${ }^{6}$

This policy is aligned with the Education White Paper 3: A Programme for the Transformation of Higher Education of 1997, published to encourage higher education institutions to be more committed to contributing to community development. ${ }^{24,27,28}$ They are tasked with shifting higher education institutions away from a racialised past towards a society driven by democracy and positive social relations. South Africa's higher education institutions are therefore tasked with contributing to economic transformation, producing a critical and vibrant society and eradicating social issues in the post-apartheid system..$^{23}$ These institutions are to demonstrate social responsibility according to the needs of the community and by availing resources to the community. ${ }^{29}$ Kitching ${ }^{30}$ highlighted the fact that, in response to the call for transformation of higher education, the Joint Education Trust launched an initiative in 1999 called the Community-Higher Education-Service Partnerships. The aim was to assist higher education institutions to conceptualise and implement community engagement as one of their core functions. ${ }^{30,31}$ The institutions were tasked to create a platform for encouraging social and civic commitment. ${ }^{29}$ With responsibility for being more engaged and available for societal benefit, they need to ensure that relevant and effective policies are developed to facilitate community engagement within higher education institutions. In the operationalisation of policies, community engagement should take place and the community's voice be nurtured. Penfold and Goodman ${ }^{32}$ observed that several South African universities responded to the Department of Higher Education's call for transformation by compiling and publishing community engagement policies, outlining their definitions of community engagement and their approaches to it. ${ }^{32}$

Bender ${ }^{33}$ presented three conceptual models that explain how South African higher education institutions perceive community engagement. All three conceptual models (silo, intersectional and infusion) address the concept of community engagement. The silo model regards community engagement as voluntary and separate from the core function of the university. The infusion model is based on the view that community engagement influences the three main functions of the university and that the main functions also influence community engagement. Finally, the intersecting model believes that community engagement intersects with the three functions of research, teaching and learning and that they influence one another.

These three models present the relationship between the higher education institutions and community engagement and how they view one another. However, the models do not refer specifically to participation, collaboration and reciprocity. By contrast, Kearney's ${ }^{34}$ Context-Focus-Profile model focuses on participation, collaboration, reciprocity and how to encourage these in the community. This approach emphasises more engaged and participatory methods for community engagement, because engagement between higher education institutions and the community should be transparent and reciprocal. Mutual trust and respect should also exist. This model reflects characteristics of an 'engaged approach' where there is more focus on and authority given to the people/communities. ${ }^{34}$ The proposed objective of the present study takes its cue from this engaged approach, because this research explores the community's perceptions of community engagement in this higher education institution with reference to the NWU's WIN.

The Context-Focus-Profile model specifically indicates three levels of engagement. The first focuses on the 'workload profile', which consists of research, service and teaching. This level focuses on the practicality of 'engagement' ${ }^{34}$ The second level focuses on the engagement itself, that is 'working collaboratively with the community to enhance educational opportunities, which can be achieved when the context of engagement is understood, encouraged and valued'. The higher education approach should be to focus on the perceptions of the community in order to develop better strategies that will pave the way for better community engagement projects. ${ }^{34}$ The third level looks at the context of the engagement, which consists of mutuality, reciprocity, transparency, trust and respect and all of which are fundamental to engagement. It is important for higher education institutions to engage with communities on the third level. This model for higher education institution community engagement provides a theoretical background on how these institutions function, how they interact with communities and how they should interact with the community to encourage participation. This information guided the empirical research in this study.

\section{Methodology}

The objective of this study was to explain the Vaalharts community members' perceptions of community engagement in the NWU WIN platform projects. For this purpose, a qualitative design was chosen. According to Krathwohl, ${ }^{35}$ 
qualitative research is naturalistic and allows for the lived experiences of people to be explored. Qualitative research focuses on the reporting of experiences and the description and interpretation of reality. ${ }^{36}$ The design took the form of a case study. Yin ${ }^{37}$ defined a case as 'a contemporary phenomenon within its real-life context, especially when the boundaries and context are not clear and the researcher has little control over the phenomenon and context' (p. 1). A case study, therefore, is the empirical investigation of a case in which descriptive questions are addressed in terms of the phenomenon under investigation. ${ }^{37}$ According to Yin, ${ }^{37}$ case study methods are advisable for use when a contemporary phenomenon relating to real-life experience/context is analysed.

The population of this study comprised the community members of the Vaalharts region (Sekhing, Pampierstad and Jan Kempdorp), who had experience of the projects. The study adopted purposive and snowball sampling as methods to generate participants. Purposive sampling was used to select and identify people with knowledge and experience of the phenomena explored ${ }^{38}$ and to select members who had previously participated in the different WIN platform projects. In addition, using snowball sampling, fieldworkers and coordinators were asked for referrals to other members who they knew had participated in the projects. These samplings identified the interviewees for the data collection conducted in June 2017 and July 2018. All participants agreed to take part in the study and consented to recordings being made of both focus group discussions and individual interviews.

The data for June 2017 were collected in collaboration with the Human Sciences Research Council (HSRC), because the WIN platform had been identified by the HSRC as a Living Lab, a concept used for centres that integrate research and innovation processes with public and private partnerships. ${ }^{39}$ The HSRC aimed to investigate the changes that the WIN platform projects had brought about in the community. Owing to the similarities in research objectives, the HSRC agreed that data from their research could also be integrated in the present study. The HSRC data collection took place in mid-2017 and took the form of 6 individual interviews and two focus-group discussions with 27 participants.

Additional data were collected in July 2018. It was planned that the sample would consist of 40 participants in total, to be equally divided between individual interviews (20) and focus groups (20). Although the expected sample size for the focus groups was reached, only 13 participants had individual interviews. The interview target of 20 was not met because many of those available for interviews had participated in just one of the projects (Community HealthCare Workers) and the diversity of the WIN platform projects was not as fully represented as anticipated. (The difficulty was because of the fact that the projects had started in 2011 and many people who were involved earlier had moved out of the area.) As a result, the decision was taken to stop the individual interviews at 13 participants when saturation was reached. However, the data collection in July 2018 covered the following range of WIN projects: Community Health Care, Workers Come Dine with Me, Community Healthcare Workers, Sustainable Diets, Programme to Support Pro-poor Development (PSPPD), Food Security, Consumer Rights, Recycling project, Sewing project, Home Based Care and Life Plan.

The two rounds of data collection raised the validity of the data and ensured better understanding of the perceptions of community members. In both cases, semi-structured interview schedules were utilised. In the first round, the focus of the interviews was on the principles of community engagement, namely collaboration, empowerment and participation. In addition, the ways the projects were implemented were also evaluated. In the second round, the interviews took a broader scope in the collection of data. The themes of the Context-Focus-Profile model were followed, meaning that a wider scope of perceptions on the community engagement was collected. In this round, the focus was on the community members' perceptions of effective community engagement, implementation, evaluation, monitoring, collaboration, participation, mutuality and reciprocity. The interviews were conducted in Tswana, because most people in Vaalharts are Tswana-speaking, but some responded in English. The fieldworkers' mother tongue was Tswana and they were also fluent in English.

\section{Findings}

In this section, the findings of the two separate data collection sessions are presented in combination. The themes were taken from the Context-Focus-Profile model and focussed on the community members' perceptions on effective community engagement, implementation, evaluation, monitoring, collaboration, participation, mutuality and reciprocity.

\section{Effectiveness of the well-being innovation platform projects}

In this subsection, the effectiveness of the WIN platform projects in the community is described. The projects were deemed beneficial to the community, with participants indicating that 'it taught us good behaviour, respect and how to work together as different age groups' (Focus group 1, 2018) and that their project had:

'... taught the youth how to communicate with older people.' (Focus group 1, 2018)

Similarly, another participant indicated that she:

'... learned that I should know how to work together with younger people.' (Interviewee 10, 2018)

This point is elaborated further in the next sections on learning skills, empowerment and meeting expectations.

\section{Skills}

The community members reported on a variety of skills they acquired from the projects. For example, a participant from the Consumer Rights reported that: 
'... we learned customer care, how to deal with complaints from people.' (Focus group 3, 2018)

Others also learned:

'... doing SWOT analysis.' (Focus group 2, 2018)

The project on sustainable diets, specifically, helped the community with diets for rural and resource-poor communities and 'eating healthy' and participants also indicated that they:

'... learned a lot of things because there were times where we just ate and were not aware of what we were eating, so we learned about measurement.' (Focus group 2, 2018)

It seems that the community benefitted from dietary information, as one participant explained:

'Taking part in the project has really helped me with weight loss, because I have learned from the projects that I have to limit my food consumption.' (Interviewee 13, 2018)

Another indicated that the project:

'... taught me how to eat properly ... even if you do not have money for breakfast, you can find cheap substitutes for lunch and supper.' (Interviewee 2, 2018)

In addition:

'... they learned to do the gardens at home and benefit from the garden.' (Interviewee 10, 2018)

A participant also indicated about the Sewing Project that:

'I have improved sewing skills.' (Focus group 1, 2017)

This project provided sewing skills and equipment as well as training manuals. Another participant listed the benefits and/or skills that the Life Plan project had added to her life:

'I am very informed; I know more about personal discipline; I have learned or acquired hygiene principles; budgeting and the project has built self-esteem.' (Interviewee 4, 2017)

The Life Plan project focussed on health and life choices.

Human capital was also built through appropriate skills development. Participants shared the view that the projects had taught them:

'... how to pass down generational knowledge to the younger.' (Focus group 1, 2018)

Their project was able to create a platform for knowledge exchange, as one participant remarked:

'The project reminded me of my culture and who I am, what my parents used to do.' (Focus group 1, 2018)

It also:

'... made me to interact more with the community. I learned a lot of things that I was unaware of.' (Focus group 1, 2018)

This result was achieved because the project taught the participants to:
'... learn to cook Setswana cultural foods.' (Focus group 1, 2018)

Because the objective was to teach both young and old people about cultural foods.

\section{Empowerment}

Empowerment relates to benefits, skills or achievements that the community had gained from the WIN projects. The projects received positive feedback in this regard. The participants acknowledged the value of all the projects as tools to empower the society.

One said:

'I also like that they wanted to share knowledge with the community and did not keep everything to themselves.' (Focus group 2, 2018)

A participant added that the project was helpful:

'... because people are struggling with self-esteem, so when such projects come it gives them hope and excitement that at least they are also remembered.' (Interviewee 2, 2018)

Participants pointed out that the projects played a role in empowering the people. As a participant explained:

'... these projects uplift them and show them that they are also important and should not give up just because they are in rural areas. So, these projects helped them to progress themselves.' (Interviewee 2, 2018)

This view was confirmed by a participant whose life had been transformed:

'It taught me life skills and how to live this life ... because I was a person that was easily angered and I wanted to get physical, so now because of this project I can control my anger and I have self-esteem now and can now see the changes in my life and how this has been relevant in my life.' (Interviewee 5, 2018)

Some participants indicated that the community struggled with unemployment and suggested that the projects should encourage 'job creation', explaining further their desire for 'economic changes to benefit everyone' (Focus group 1, 2017).

The same point was made in an interview:

'... the community needs to learn how to create their own employment.' (Interviewee 4, 2018)

The projects themselves did not offer employment, but participants confirmed that the projects encouraged workrelated skills and independence, stating that:

'We were able to venture and start a cooperative in poultry production, gained knowledge and skills to open youth cooperative.' (Interviewee 3, 2017)

A participant from the recycling project, who collected plastic bottles and other recyclable products, indicated that 'I am able to budget the income from the recycled products and use it for household expenses' (Focus group 2, 2017). Another participant felt: 
' $\ldots$ able to facilitate health work such as taking the BP (blood pressure) and door-to-door visitation to households who are taking treatment in the nearby clinics.' (Interviewee 6, 2017)

Participants gave examples of learning acquired, such as:

'I gained knowledge in health issues or hygiene and how to be a principled health care worker.' (Focus group 1, 2017)

The Come Dine with Me project in the village of Sekhing had encouraged the community members to create their own initiatives. One participant said:

'After the project we then decided that we are going to ask the royal King to give a centre where we can practice cultural things.' (Interviewee 3, 2017)

The findings indicated that the Sustainable Diets project, specifically, had positively influenced older people. This was because, as participants indicated, the projects had:

'... improved healthy lifestyle of the community, with regular exercise, like older people playing soccer.' (Focus group 2, 2017)

'... older people are able to do day-to-day chores without assistance from anyone due to healthy eating schedules.' (Focus group 2, 2017)

The project was also said to have improved the well-being of community members because:

'... it has increased activeness and reduced tiredness from participants above 50 years' through the healthier diet that they had adopted. In addition, one participant observed: "Healthy eating programmes decreased sickness."' (Focus group 2, 2017)

Other examples of empowerment were also mentioned. A participant who was a motivational speaker said:

'I have also acquired more information on dietary through the Salt Project; my self-esteem is boosted and assisted in being wellrespected within the community.' (Interviewee 2, 2017)

A participant from the Consumer Rights project said it had:

'... opened my mind to the fact that I have rights to return the product if it has passed the "best before" date and actually take action against that.' (Interviewee 12, 2018)

Another participant added:

'... when I now go to the shop I know what and how to check food and I know how to budget.' (Interviewee 11, 2018)

A participant from the Community Healthcare Workers project reported that:

'... we have only one assistant nurse, and when she is sick or at training, they have to do everything themselves and that takes time. So, we came in and helped in that area, so that everything goes quicker.' (Interviewee 8, 2018)

The Sewing Project had taught the participants business skills and provided them with additional booklets to take home. One participant pointed out the benefits of this approach:

'... when we were attending the workshops they would give us books and information, so when I got home I would sit and read the books again and actually apply the knowledge in solving my own problems.' (Interviewee 12, 2018)

Another participant described practical advantages to the community:

'I can help a lot of people, because people are struggling in our community. I want to make their lives easier, if they need their clothes to be sewed, they do not need to catch a taxi, and they can just bring it to me.' (Focus group 1, 2018)

A need was expressed for youth in particular to be empowered further by WIN projects. Participants said they wanted 'to see the Sesotho tradition being embraced by the youth wearing their Sesotho clothes and dances'. Young people in Vaalharts - like many others in the country - abused alcohol and drugs. Participants suggested that their community needed projects to address such problems and that it would:

'... prohibit the use of alcohol and drugs [and bring about] control of late-night taverns.' (Focus group 2, 2017)

The community felt they need more educated youth, which indicated a desire for more training, workshops, and libraries in the community to facilitate educational advancement (Focus group 2, 2017).

It seems, therefore, that the participants in general experienced the WIN platform projects or interventions as empowering, but would like to see a stronger focus on young people.

\section{Expectations}

The participants expected the projects to benefit them. Asked what could be improved regarding the WIN platform, a participant suggested that the projects should:

'... establish something in the community that will last for a long term, for example a centre that the community can get involved in projects that the community has and projects that comes from the university. The centre will assist in that the skills that people acquire from the projects can be implemented and therefore be sustainable.' (Interviewee 2, 2018)

The idea was that the participants would run the centre and allow people from the community to go there to acquire skills that the participants had already acquired from the WIN platform projects, such as cooking, sewing and basic life skills from the life plan projects. Participants added that this centre should be open to anyone with skills who wants to teach the community something, such as welding (Focus group 1, 2018). A further request was for community members to receive from the university a proof of completion or participation in the projects to indicate the skills and knowledge they had received. Accredited certificates could be presented when applying for jobs (Interviewees 8 and 10, 2018).

This subsection revealed participants' perceptions of the effectiveness of the WIN platform projects in developing 
skills, empowering community members and meeting expectations. Although the projects developed skills and empowerment, they did not fully meet expectations. Appreciation for the projects' interventions was expressed, but in terms of setting goals, the projects seemed insufficiently focussed on the self-determination of community members. It was felt that a more equal distribution of authority may have given participants the platform to identify the challenges they faced and the roots thereof and greater encouragement to develop their own solutions and action plans on how to tackle these issues. ${ }^{8}$

\section{Implementation}

This subsection reflects on the participants' positive and negative perceptions of the way the projects were implemented and managed.

\section{Positive perceptions}

Positive perceptions indicate that the WIN platform projects implemented the projects in ways that were satisfactory and relevant to the people and their environment. These perceptions were influenced according to whether the participants felt respected personally or whether the WIN platform respected their fields of work. The participants were asked to comment and one participant shared the view that:

'... yes, the community was treated with respect, because when the projects began it was introduced at the royal council with the traditional leaders, it did not just come in without the consent of the leaders.' (Interviewee 2, 2018)

Such responses confirmed that the university had followed a formal procedure relevant to the Sekhing community when implementing the project as, for example, in the Come Dine with Me project presented in Sekhing, a traditional village still under leadership of the royal council.

Participants from other projects indicated that they had the opportunity to take part in the planning phase of the project. One said: 'yes, I had a chance to give my ideas for the project' (Interviewee 12, 2018). Another indicated that:

'... yes, I would suggest ideas to them for when they come into the community, and they would listen.' (Interviewee 12, 2018)

The WIN platform thus allowed participants to share their ideas regarding how the projects could be implemented and offered assistance when required:

'... if there was a problem, they would send one of the assistants to come and check up on us.' (Interviewee 1, 2018)

\section{Negative perceptions}

Some participants felt that the community had not been fully involved in the planning phase. One participant said:

'... they should come to us and ask us which project we want, because we are the ones who are staying here.' (Interviewee 8, 2018)

\section{Another indicated that:}

'... the project honestly came to the community up and running, there was no planning phase. We were just informed that there is a project that is coming and what it wanted to address.' (Interviewee 2, 2018)

A further participant concurred:

'.. they came with the projects already developed, they just told us when they will be coming to the community. So, we would only sit down with them and agree with the project and proceed.' (Interviewee 12, 2018)

Some community members complained that the selection of participants was unfair (Interviewee 12, 2018) and that project numbers were limited just to a certain number of people (Interviewee 5, 2017, and Interviewee 12, 2018). Come Dine with $\mathrm{Me}$, for example, was described as involving only a limited number of youths as mainly older people took part in the project, fewer young people could benefit from the skills taught. A participant suggested:

'... the projects should always choose the same loyal people, as we were loyal in the first project, they should have chosen us for the second one as well. But they did not, so we felt like we were not good enough when they chose other people.' (Interviewee 3, 2018)

In similar vein, it was indicated that:

'... yes, they should involve the same people, because when they do not choose us, I started doubting myself thinking it is because I finished school in grade 8.' (Interviewee 3, 2018)

A community member mentioned an instance in which a university student was disrespectful towards them (Interviewee 3, 2018), but another expressed the opposite perception of the project:

'It made us feel like we are wanted and needed as community health care workers.' (Interviewee 8, 2018)

A few expectations emerged about how future projects should be implemented because some participants felt reluctant to join in on the grounds that projects were used by the stakeholders for their own personal gain. They suggested that there should be:

'... no corruption ... nepotism should be prohibited [and] the community must be comfortable in working with them through this project, so that poor participation can decrease.' (Focus group 2, 2017)

These comments indicate that key objectives were not always clearly enough defined when participants could not outline how the projects were meant to benefit them, as participants and the community at large. Most participants had believed that the projects would bring 'job creation' and they had expected to have 'secured jobs' and 'poverty alleviated' (Focus group 1, 2017).

Perceptions about the implementation of the projects were diverse. Some were positive and appreciative about the implementation process. Others felt that the university could have consulted more and should have involved more people. 


\section{Evaluation and monitoring}

Evaluation and monitoring are important aspects of a project. Lack of these can lead to unhappiness and even project failure. One participant observed that:

'... some objectives were not met due to lack of monitoring and evaluation.' (Interviewee 3, 2017)

The community saw benefit in the close monitoring of the projects by the WIN platform team and one participant wanted:

'... to have someone there who knows better, that can guide me through the process on what to do and what not to do.' (Focus group 1, 2018)

Another participant shared the thought that:

'... for example, when we are busy with the activities, you guys can go with us, to monitor and evaluate us while we are busy. Because when you are lenient, people tend to not take things serious and end not doing it well.' (Interviewee 11, 2018)

Another participant complained that the WIN platform did not keep to their schedule:

'I think it was on the third or fourth day, when they were getting tired now because everything was going fast. They must learn to stick to their schedule, if they say five days for a workshop, it must be that full five days, they must not shorten the time because of other constraints because we need them.' (Interviewee $8,2018)$

Community members clearly valued the evaluation and monitoring of projects, as well as their implementation as planned.

\section{Collaboration}

Collaboration is the core of effective community engagement because it enhances the ethics of working together to achieve the task at hand. ${ }^{12}$ Collaboration was indicated in terms of the partnerships and effective relationships that were encouraged by the WIN platform projects. Two interviewees saw the university as capable and knowledgeable to develop projects for the community and, therefore, thought that the initiative must come from the university (Interviewees 9, 13, 2018). Others emphasised collaboration with the university:

'I think when the university comes to the community we can group ourselves and give them our ideas and maybe they will love them and they might create a project from them.' (Interviewee 7, 2018)

'I think both the community and university should come with ideas, collaborate and take it from there.' (Interviewee 7, 2018)

Collaboration between the community and the university was also requested at the practical level. For example, it was suggested that:

'... the university could come and we do a walk around the community and do health awareness by taking BP and other health sciences. Because the community recognises us because of the students from the university.' (Interviewee 4, 2018)
The findings made it clear that collaboration was prized by the community members.

Of interest was the fact that participants were outspoken about the broader cooperation that they experienced in the projects. The Community Healthcare Workers project, for instance, had helped them to improve their working relationships with their clients, as the projects:

'... improved communication skills with patients during rounds in community health work and better relationships with clients.' (Interviewee 6, 2017)

Other participants perceived the projects as having encouraged participation with others in their personal lives, as the projects PSPPD and Food Security were able to:

'... bring me into contact with other people who work in the same area, which encouraged participation in the workshop.' (Interviewee 1, 2017)

'I learnt how to work with the community.' (Interviewee 1, 2017)

Participants advocated for collaboration within the community, indicating that there should be:

'... togetherness of women and children to open community groups.' (Focus group 2, 2017)

Collaboration should also extend to government departments, as indicated by a participant from the Come Dine with $\mathrm{Me}$ and Sustainable Diets projects who wanted the:

'Department of Health to be more involved.' (Focus group 2, 2017)

Because they lacked money and resources, participants also asked for:

'... funding from the stakeholders and NGOs.' (Focus group $2,2017)$

So that they could start:

'... selling the Sesotho traditional food [and] have small backyard gardens.' (Focus group 2, 2017)

Some positive results emerged from feedback on collaboration. The projects were viewed as having brought the community together and taught them teamwork and interdependency. That being said, the community still wanted more involvement and support from other structures in the community such as the Department of Health, nongovernmental organisations and community members.

\section{Participation}

Community participation has been defined as the direct involvement of ordinary people in planning, governance and overall development programs at the grassroots level' ${ }^{40}$ This had not been fully realised within the WIN platform projects because the goals and key objectives of the projects were not all clearly defined to the community at the initial stages. Community members' lack of participation in the initial stages caused some uncertainty about the main objectives of 
the WIN platform projects. Participation issues are further described in the following subsections on communication, constraints in involvement and reasons for participation.

\section{Communication}

Communication was satisfactory for some participants:

'Yes, I felt comfortable and part of the project and there were no miscommunications.' (Interviewee 2, 2018)

'I was given a chance to give my views at the WIN project workshop on which projects can be beneficial to the community.' (Interviewee 2, 2018)

But others indicated gaps:

'... not a lot of people know about the WIN platform, because I also did not know up until I was invited.' (Interviewee 2, 2018)

'... the only project that they were familiarised with was the one of sustainable diets, so they thought it is only one project but I later discovered that there are many projects that the university is doing in the community.' (Interviewee 8, 2018)

It is possible that the WIN platform did not use all formal channels of communication:

'I would not want to answer that because the community should be informed by the municipal community councillors. So, I do not know if they knew of the projects or if they even participated.' (Interviewee 12, 2018)

\section{Constraints in involvement}

Participants were asked for constraints they faced in their communities to participate in the projects. The Vaalharts community is poor, to which the participants attested, indicating that:

'... the challenge is that in this community we are disadvantaged.' (Focus group 1, 2018)

'... another issue is that we live in the villages and things are not as easy as they are in the locations and cities.' (Focus group 1, 2018)

These conditions were given as a reason for poor participation, because:

'... poverty hinders the project's success.' (Interviewee 4, 2017)

Lack of rewards made people reluctant to participate. Also, community members did not have the means to get to the facilities where the projects were hosted and they said:

'... we expected transportation to the activities.' (Focus group 1, 2017)

Age and educational level were identified as common constraints for participants to understand the project fully

\section{Reasons for participation}

People participated in the projects for different reasons. Many hoped for employment or stipends, as was explained by a participant:

'... with me I expected that the projects would give us job opportunities, not a permanent job but something; if not, I expected them to take people to workshops and training.' (Interviewee 7, 2018)

Another participant said:

'... the thing is that in our community we struggle with unemployment and poverty.' (Interviewee 12, 2018)

In general, the community had hoped that the WIN platform would improve their lives. A participant indicated appreciation:

'... at some point these projects bring light to the rural areas.' (Interviewee 2, 2018)

Other participants agreed, saying that:

'... because there are not a lot of people that have the skills to teach our people, even children in school I do not think they get taught these things.' (Interviewee 3, 2018)

Such projects:

'... bring some sort of activity to the village because there are no jobs.' (Focus group 1, 2018)

A participant elaborated further:

'... some of us did not even go to university, so when the university comes to us people who are at a low level, we appreciate and we get uplifted.' (Interviewee 3, 2018)

Another person emphasised the gaps that had to be filled:

'We need help from experts or those that have knowledge about such.' (Focus group 1, 2018)

\section{Future participation}

The community was willing to participate in future projects of the WIN platform. Participants were eager to continue:

'Yes, I would have interest, as long as I am alive.' (Focus group 1, 2018)

'Yes, because I love changing people's lives and making an impact in the community.' (Focus group 3, 2018)

The prospect of future participation was also associated with personal development:

'I would, because in these projects we learn things we are not aware of and things that we sometimes not take into consideration. I have learned a lot of things, from health care to financial education.' (Focus group 3, 2018)

In a poor community, participation creates specific challenges. Communication is in such an environment very important and the WIN projects could improve in that respect. Poverty was another factor that constrained participation. However, in general, the projects were viewed as advantageous for the community and participation was, therefore, valued.

\section{Mutuality and reciprocity}

In community engagement projects, mutuality and reciprocity are important. Mutuality is associated with commonality, shared feelings and activities in a partnership. ${ }^{41}$ Janke and Clayton ${ }^{17}$ defined reciprocity as the recognition, 
respect and valuing of the knowledge, perspective and resources that each partner contributes to the collaboration'. One participant put it succinctly:

'... the university came to help us with things we do not know so we also help them.' (Interviewee 5, 2018)

The goals of the WIN platform matched some of the participants' personal goals and interests, as was indicated in an interview:

'I am a person who loves to learn, this project even found me busy with an NPO. This is because I love working with the community and helping people.' (Interviewee 2, 2018)

The community of Vaalharts struggled with long queues at the clinic that caused stampedes and there was appreciation that through the healthcare workers project, these queues could be reduced:

'... they wanted to cut down on the long queues at the clinics and address those people that stay very far.' (Interviewee 8, 2018)

Mutuality is associated with commonality and shared feelings that ensure beneficial relationships. Participants recognised that effort came from both parties:

'I think it is because they also want to learn more about culture, and it was so amazing because they came already dressed in traditional clothes.' (Interviewee 3, 2018)

The community participants indicated in different ways the mutuality they experienced in terms of their personal goals or interests:

'I enjoyed it because I have always wanted to be a nurse.' (Interviewee 4, 2018)

'I love cooking and was interested.' (Interviewee 5, 2018)

'It was very good, because sometimes if you do not do something practical and you just do theory, you seem to forget. So it was nice when she gave us a chance to take vitals and do practicals, for me it was like a refresher course.' (Interviewee 8, 2018)

'We are very happy and wish that it would continue to teach us and our children to understand traditional ways of cooking. Because this young generation does not understand ancient cultural ways as we do.' (Focus group 1, 2018)

Although the projects were initiated by the WIN platform and were largely conceptualised unilaterally, community members had experienced recognition and the valuing of their perspectives. This element can be improved in future projects.

\section{Overall project satisfaction}

The community was asked to express their overall satisfaction with the projects through drawings. Each of two focus groups drew a picture depicting the way in which the projects had impacted their lives. This activity was designed to allow participants to express their experience of the projects by other than just verbal means.

The drawing ${ }^{42}$ in Figure 1 came from the focus group in Sekhing, which was involved in the Come Dine with Me

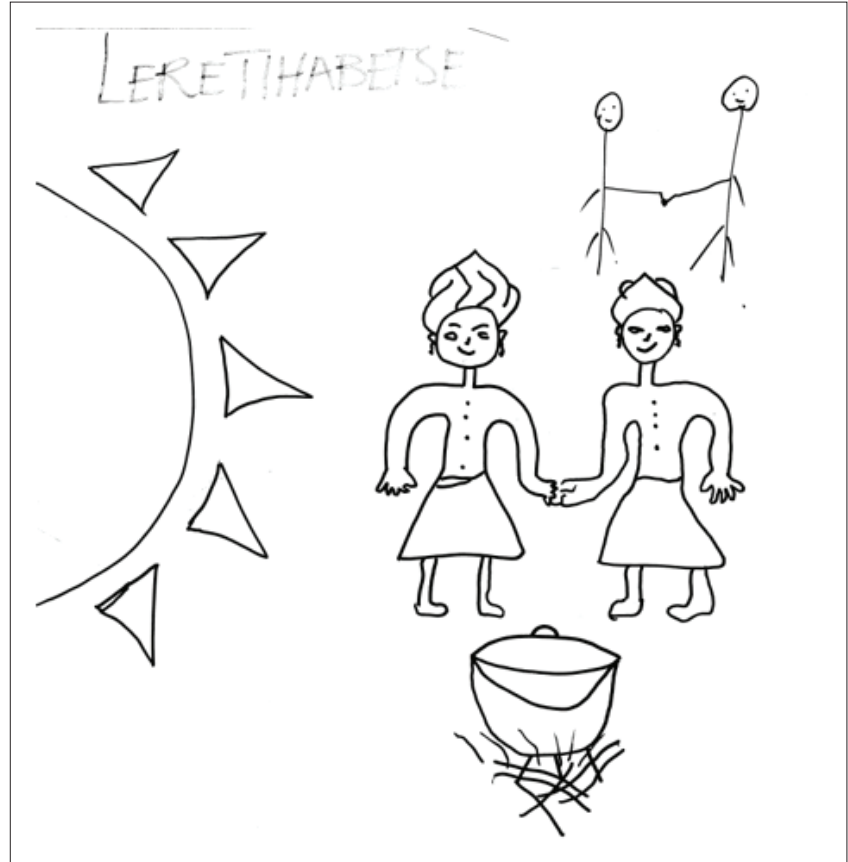

Source: Sebeco L. Community members' perceptions of higher education institutions' community engagement projects: The case of the WIN platform of the North-West University [Unpublished dissertation]. Potchefstroom: North-West University; 2018

FIGURE 1: Sekhing focus group drawing.

project. They drew two women holding hands and a pot on an open fire, which for them symbolised the teamwork that the project had encouraged. The development that had been experienced is depicted by the stick drawing of the two women turning into full body drawings. The sun and the heading leretlhabetse (which means 'it has shone for us') indicates the light that the project brought to the community through the opportunities and direction that had been experienced by its members.

Figure 2 was drawn by the focus group ${ }^{42}$ involved in the Community Healthcare Workers project in Jan Kempdorp, which had included Life Plan, PSPPD and Home-based Care. The participants depicted the feelings that the WIN platform projects had evoked in them. They drew a flower and a smiley face, which indicate happiness. They also drew a butterfly, which symbolises the fact that that the projects gave them wings to fly through the new knowledge that they had provided to the community. The last indicator was the heart, which symbolises the love they had for the WIN platform team.

\section{Evaluative remarks}

The Context-Focus-Profile model offers guidance for higher education engagement as they collaborate with communities and ensure mutuality, reciprocity, transparency, trust and respect in the relationship. Did the WIN platform projects succeed? From the responses of the community members, as presented in this paper, it is clear that some of the goals were accomplished. Community members acquired skills and applicable knowledge, through which empowerment did indeed take place, and members reported enhanced 


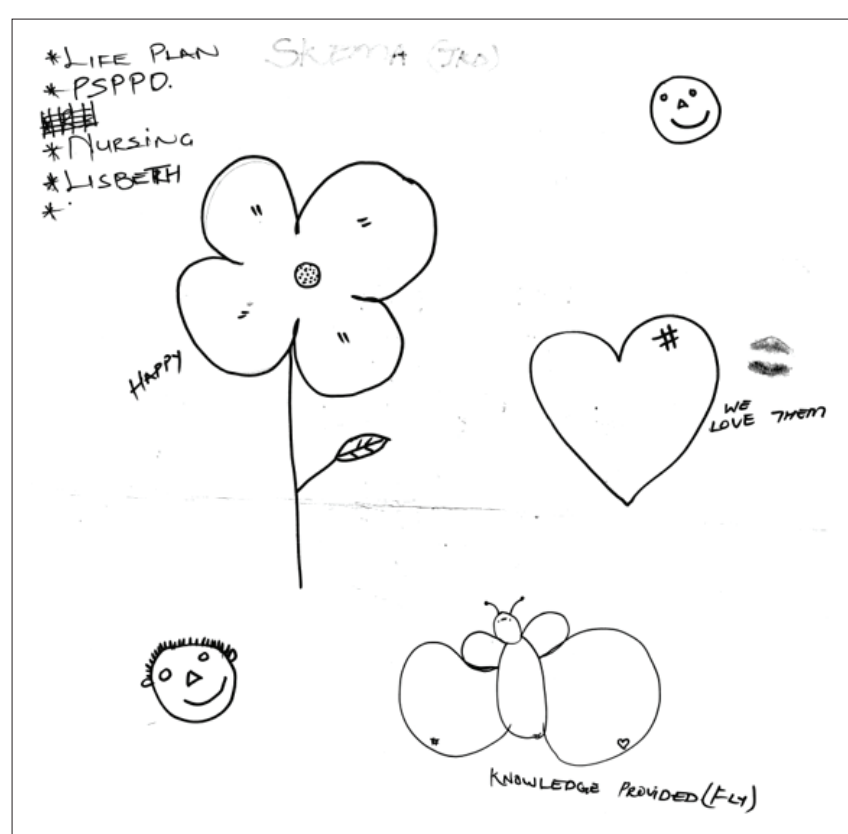

Source: Sebeco L. Community members' perceptions of higher education institutions' community engagement projects: The case of the WIN platform of the North-West University [Unpublished dissertation]. Potchefstroom: North-West University; 2018

FIGURE 2: Jan Kempdorp focus group drawing.

self-esteem and self-confidence. They also reported that the projects resonated with needs in the community and were therefore beneficial. The projects also attempted to keep communication channels open and success was to a certain extent achieved. In general, the community reported satisfaction with the projects.

However, the projects could improve their engagement with the community. The Vaalharts community is poor and vulnerable and its members therefore expect that projects will speak to those needs. For that reason, it is important to involve the community from the conceptualisation of the projects through their implementation and to preclude misunderstandings and erroneous expectations. It is also important for the community to feel respected and therefore comfortable about providing project input. Of further importance is continuing monitoring and evaluation, designed to pick up any problems in the implementation of projects and to determine whether or not they meet their objectives, especially in terms of relationship with the community. This engagement was lacking in the projects presented thus far. For long-lasting interventions, the success of the projects must be assured and good communication is critical. The extent to which community members are involved in projects needs attention. According to the participants, only a limited number of community members were engaged in the projects and the youth, with their major needs for development, were not fully catered for. In general, the findings from this study showed that projects aimed at vulnerable people must be managed in such a way that the target group feels respected and that it collaborates fully in the planning, implementation and evaluation of the projects to ensure they match the people's needs. This study confirms the value of using the
Context-Focus-Profile model to obtain an in-depth evaluation of higher education institutions' engagement with communities.

The study was limited in that participants from all the WIN platform projects could not contribute, so it could not offer a full evaluation of all the projects. Nevertheless, it provides a sufficiently clear indication of the participants' experiences of their own projects to suggest areas that could benefit from improvements in future and areas that community members perceived as having achieved success.

\section{Conclusion}

This study reported on community members' evaluative perceptions of the community engagement of the WIN platform. Although a limited number of participants in the projects contributed to the research, they gave valuable insights into how the community perceived the projects. This information made it possible, using the Context-Focus-Profile model, to evaluate different aspects of a higher education engagement with a community, in this case specifically with regard to the WIN platform projects.

In general, the community members' perceptions of the projects were positive. They were well received by the community and were seen to contribute in particular to improvement of skills and self-development. However, poverty made the people of the communities vulnerable. In such circumstances, to ensure enduring benefits, it is important to build a close engagement with the community - in this respect, there is room for improvement. This study identified specific areas for further development and it also demonstrated the value of using the Context-Focus-Profile model for this kind of evaluation.

Community engagement is high on the agenda of higher education institutions. This study reports on ways in which a community experienced such engagement. In doing so, it also contributes to the larger debate about the role of higher education in the broader South African society.

\section{Acknowledgements}

The authors would like to acknowledge the permission and support of the WIN platform of the Africa Unit for Transdisciplinary Health Research in the Faculty of Health Sciences at the Potchefstroom Campus of the NWU to conduct this research. The guidance and inputs in discussions with Dr Nicole Claasen and Dr Gift Mupambwa on this research are also acknowledged.

\section{Competing interests}

The authors declare that they have no financial or personal relationships that may have inappropriately influenced them in writing this article. 


\section{Authors' contributions}

This article was written by J.Z. based on the research conducted by L.S. L.S. conducted this research towards a master's degree under the supervision of J.Z.

\section{Ethical considerations}

Ethics approval for this study was granted by the NWU Research Ethics Regulatory Committee, NWU-00433-18-A7.

\section{Funding information}

The National Research Foundation's financial support for this research is acknowledged with appreciation.

\section{Data availability}

Original data were collected and analysed in this study. Although the data used in this study are available, both the HSRC data and the original data are confidential and therefore not generally available.

\section{Disclaimer}

The views and opinions expressed in this article are those of the authors and do not necessarily reflect the official policy or position of any affiliated agency of the authors.

\section{References}

1. AUTHeR: WIN platform. NRF proposal for funding 2017-2019. Unpublished; 2017

2. Mtawa NN, Fongwa SM, Wangenge-Ouma G. The scholarship of universitycommunity engagement: Interrogating Boyer's Model. Int J Educ Dev.

3. Ramachandra A, Mansor NNA. Sustainability of community engagement - In the hands of stakeholders. J Educ Train. 2014;56(7):588-598. https://doi.org/10.1108/ ET-07-2014-0084

4. Centre for Higher Education Transformation (CHET). Terms of engagement: Renewing the role of the university as an urban institution [homepage on the Internet]. 2003 [cited 2018 Sep 2]. Available from: https://www.chet.org.za/files/ CHET\%202003\%20Terms engagement.pdf

5. De Lange G. Developing a university-community engagement conceptual framework and typology: A case study of a South African comprehensive university. Africa Insight. 2012;42(2):94-111.

6. NWU (North-West University). Community engagement policy [homepage on the Internet]. 2016 [cited 2017 Aug 10]. Available from: http://www.nwu.ac.za/sites/ www.nwu.ac.za/files/files/i-governance-management/policy/10P-10.4 Community $\% 20$ Engagement $\% 20$ Policy_eng.pdf

7. Attree $P$, French B, Milton B, Povall S, Whitehead M, Popay J. The experience of community engagement for individuals: A rapid review of evidence. Health Soc Care Community. 2011;19(3):251. https://doi.org/10.1111/j.1365-2524.2010.00976.x

8. Glandon D, Paina L, Olonge O, Peters DH, Bennett S. 10 best resources for community engagement in implementation research. Health Pol Plann. 2017;32(1):1457-1465. https://doi.org/10.1093/heapol/czx123

9. Setswe G, Witthuhn J. Community engagement in the introduction and implementation of national health insurance in South Africa. J Publ Health Af 2013;4(6):27-31. https://doi.org/10.4081/jphia.2013.e6

10. Bringle RG, Hatcher, JA. Campus-community partnerships: The terms of engagement J Soc Issues. 2002;58(3):503-516. https://doi.org/10.1111/1540-4560.00273

11. World Bank. Issues and options for improving engagement between the World Bank and civil society organisations [homepage on the Internet]. Washington, DC;
2005 [cited 2017 Sep 14]. Available from: http://siteresources.worldbank.org/ 2005 [cited 2017 Sep 14]. Available from: http://siteresources
CSO/Resources/Issues_and_Options_PUBLISHED_VERSION.pdf

12. Omerikwa AO. Faculty construction of reciprocity and mutuality in community engaged scholarship. Unpublished dissertation. Athens: University of Georgia; 2012 .

13. Stanton TK. New times demand new scholarship: Opportunities and challenges for civic engagement. Educ Citizen Justice. 2008;3(1):19-42. https://doi. org/10.1177/1746197907086716

14. Schlake MR. Community engagement: Nine principles [homepage on the Internet]. 2015 [cited 2018 Jul 30]. Available from: https://digitalcommons.un edu/cgi/viewcontent.cgi?article=1726\&context=agecon_cornhusker
15. Cristalli CN, Dulmus ME. A university-community partnership to advance research in practice settings: The HUB Research Model. Res Soc Work Pract. 2012;22(2): 129-134. https://doi.org/10.1177/1049731511423026

16. Gilbert ED, Laedtke D, Sharp TA, Wood S, Raville L. Effective community engagement strategies: The voices of injection drug users. J Community Engagement Scholarship. 2018;10(2):44-53.

17. Janke EM, Clayton PH. Excellence in community engagement and communityengaged scholarship: Advancing the discourse at UNCG [homepage on the Internet] Greensboro, NC: University of North Carolina at Greensboro. 2011 [cited 2017 Aug 18]. Available from: https://communityengagement.uncg.edu/wp-content/ uploads/2014/07/Excellence-in-Community-Engagement-and-CommunityEngaged-Scholarship-Volume-1-Advancing-the-Discourse-at-UNCG.pdf

18. Wilson A. Towards an integration of content analysis and discourse analysis: The automatic linkage of key relations in text [homepage on the Internet]. University of Lancaster; 1993 [cited 2018 Nov 06]. Available from: http://ucrel.lancs.ac.uk/ papers/techpaper/vol3.pdf

19. Eckerle SC, Munger F, Mitchell T, Mackeigan M, Farrar A. Building effective community university partnerships: Are universities truly ready? Michigan Community Serv Learn. 2011;1(1):15-26.

20. Shannon J, Wang T. A model for university-community engagement: Continuing educations role as convener. J Cont High Educ. 2010;58(1):108-112. https://doi org/10.1080/07377361003661499

21. Jischke MC. Universities. Vital speeches of the day. 2006;72:509-512.

22. Rowe CD. The sustainability of service learning and community engagement in post 'community higher education service partnership' era [Unpublished dissertation]. Johannesburg: University of Witwatersrand; 2011.

23. Luvalo ML. The role of higher education in social transformation and rural development. Mediterr J Soc Sci. 2014;5(23):1206-1212. https://doi.org/10.5901/ mjss.2014.v5n23p1206

24. Kruss G. Reconceptualising engagement: A conceptual framework for analysing university interaction with external social partners. S Afr Rev Sociol. 2012;43(2): 5-26. https://doi.org/10.1080/21528586.2012.694240

25. Boyer EL. The scholarship of engagement. J Public Serv Outreach. 1996;1(1):11-20.

26. Hlalele D, Manicom D, Preece J, Tsotetsi CT. Strategies and outcomes of involving students in community engagement: An adaptive leadership perspective. JHEA RESA. 2015;13(1):169-174.

27. Kagisano Issue 6. Community engagement in South African higher education Pretoria: South African Council of Higher Education; 2010.

28. Akhurst J, Solomon V, Mitchell C, Van der Riet M. Embedding community-based service learning into Psychology degrees at UKZN, South Africa. Educ Res Soc Change. 2016;5(2):136-150. https://doi.org/10.17159/2221-4070/2016/ v5i2a9

29. Erasmus, M. Introduction: Community service learning and the South African research agenda. Acta Academica Supplementum. 2005;3:1-23.

30. Kitching AE. A participatory paradigm for an engaged scholarship in highe education: Action leadership from a South African perspective. Educ Res Soc Change. 2016;5(1):144-147

31. Mwaniki M. University-government-international donor community cooperation in research, teaching and community engagement. S Afr J High Educ. 2010;24(3):407-431. https://doi.org/10.4314/sajhe.v24i3.63446

32. Penfold E, Goodman S. An evaluation of a knowledge partnership - A review of the literature [homepage on the Internet]. 2011 [cited 2018 Aug 04]. Available
from: http://www.knowledgeco-op.uct.ac.za/usr/knowledgeco-op/downloads/ from: http://www.knowledgeco-op.uct.ac.za/
Penfold\&Goodman_Lit\%20Review_2011.pdf

33. Bender G. Exploring conceptual models for community engagement at higher education institutions in South Africa: Conversation. Perspect Educ. 2008; 26(1):81-95.

34. Kearney J. Educational research for social change. Challenges for community engagement: An Australian perspective. Educ Res Soc Change. 2015;4(1):26-39.

35. Krathwohl DR. Methods of educational and social science research: An integrated approach. 2nd ed. New York, NY: Longman; 1998.

36. Denzin NK, Lincoln YS. The discipline and practice of qualitative research. In Denzin NK, Lincoln YS, editors. The Sage handbook of qualitative research. Thousand Oaks, CL: Sage; 2004; p. 1-26.

37. Yin RK. Design and methods. 5th ed. Thousand Oaks, CA: Sage; 2014.

38. Patton MQ, Cochran M. A guide to using qualitative research methodology: What is qualitative research, aims, uses and ethical issues? [homepage on the Internet]. 2002 [cited 2017 Feb 04]. Available from: https://evaluation.msforg/sites/ evaluation/files/a_guide_to_using_qualitative_research_methodology.pdf

39. Feurstein K, Hesmer A, Hribernik KA, Thoben KD, Schumacher J. Living labs: A new development strategy. strategy. In: Schumacher J, Niitamo VP, editors. European living labs - A new approach for human centric regional innovation. Berlin: Wissenschaftlicher Verlag; 2008; p. 1-14.

40. Williams J. The politics of social change and the transition to democratic governance: Community participation in post-apartheid South Africa. In: Pretorius J, editor. African politics: Beyond the third wave of democratisation. Cape Town: Juta; 2008; p. 172-197.

41. Alexander CE. Mutuality and reciprocity in relationships: Generalist social workers' considerations and strategies for managing their relationships with clients. Unpublished thesis. Alberta: Calgary University; 2013.

42. Sebeco L. Community members' perceptions of higher education institutions' community engagement projects: The case of the WIN platform of the North-West University [Unpublished dissertation]. Potchefstroom: North-West University; 2018. 